\title{
Originals
}

\section{Limited benefit of treatment of diabetic polyneuropathy with an aldose reductase inhibitor: a 24-week controlled trial}

\author{
J. Fagius ${ }^{1,2}$, A. Brattberg ${ }^{1}$, S. Jameson ${ }^{3}$ and C. Berne ${ }^{3}$ \\ Departments of ${ }^{1}$ Neurology, ${ }^{2}$ Clinical Neurophysiology and ${ }^{3}$ Internal Medicine, University Hospital, Uppsala, Sweden
}

\begin{abstract}
Summary. The effects of the aldose reductase inhibitor, sorbinil, on symptomatic symmetrical diabetic polyneuropathy were studied during a 6-month period in a double-blind parallel group placebo-controlled trial. Twenty-seven patients received sorbinil and 28 placebo. The patients were assessed by clinical examination, neurophysiological measurements, sensory threshold determinations and tests of autonomic nerve function. No major clinical benefit was seen in the sorbiniltreated patients and no differences in sensory thresholds were observed. In three out of nine neurophysiological tests (motor nerve conduction velocity of the posterior tibial nerve, F-wave latency and sensory distal latency of the ulnar nerve) and one out of five tests of autonomic nerve function (heart rate variation during deep breathing) significant differences between
\end{abstract}

the patient groups evolved in favour of sorbinil treatment. An overall evaluation of the temporal development of these and remaining neurophysiological and autonomic variables suggested a small but significant benefit from sorbinil treatment. There was no evidence of continuing improvement throughout the treatment period and beneficial effects observed were no greater than those seen in previous trials of considerably shorter treatment periods. It is concluded that sorbinil treatment results in some improvement in peripheral nerve function in symptomatic diabetic polyneuropathy, but that the long-term effect may be of limited value.

Key words: Diabetes mellitus, polyneuropathy, sorbitol accumulation, aldose reductase inhibitor, clinical trial.
Polyneuropathy is a well-known long-term complication of diabetes mellitus, its prevalence increasing with the duration of the disease and reaching about $50 \%$ at 25 years [1, 2]. In 1966, Gabbay et al. suggested that formation of sorbitol from glucose in the polyol pathway underlay the pathogenesis of diabetic polyneuropathy [3]. Over the last few years a number of controlled clinical trials with aldose reductase inhibitors, which act by interrupting the accumulation of sorbitol, have been reported [4-9] and most of them have suggested that aldose reductase inhibitors have some beneficial effect on peripheral nerve function in diabetic patients. All studies have comprised short-term treatment, 12 weeks or less.

The aim of the present investigation was to study the potent aldose reductase inhibitor, sorbinil [d-6-fluorospiro(chroman-4,4'-imidazolidine)- $2^{\prime}, 5^{\prime}$-dione] [10] in male patients with symptomatic diabetic polyneuropathy of the distal, symmetrical sensori-motor type and with symptoms of sexual impotence. A parallel placebo-control group design was used. The treatment period was for 24 weeks.

\section{Subjects and methods}

\section{Subjects}

Fifty-five male patients ( 27 on sorbinil and 28 on placebo) completed the trial. Details of the patients are presented in Table 1.

Inclusion criteria were: diabetes mellitus, insulin dependent or non-insulin dependent, of at least 1 year's duration; stable diabetes (no change of therapy during the preceding 6 months); symptoms referrable to symmetrical polyneuropathy; decreased nerve conduction velocities in the legs as evidence of polyneuropathy (see Table 3 for normal values).

The two groups were comparable as to number of patients and duration of diabetes and symptoms (Table 1 ). There was a considerable range of duration of diabetes and polyneuropathy in both groups, illustrating that they were heterogenous.

Patients with other possible causes of polyneuropathy were excluded. Thus, at the first visit, in addition to laboratory tests (see below), serum gamma glutamyltransferase, cobalamin and thyroxin levels were measured. Levels of serum creatinine or urea above the refer. ence limits for normals were exclusion criteria as signs of renal insufficiency, but patients with macroalbuminuria $(>250 \mathrm{mg} / 24 \mathrm{~h}$ ) were accepted. The degree of diabetic control was assessed by repeated analyses of glycosylated haemoglobin $\left(\mathrm{HbA}_{1}\right)$ and $24-\mathrm{h}$ urine glucose. The patients continued their standard antidiabetic therapy, diet plus insulin or oral antidiabetic agent, as prescribed by their ordinary physician (independent of the present study). Change of dosage was 
Table 1. Clinical details of the patients studied and the duration of disorders

\begin{tabular}{|c|c|c|c|c|c|c|}
\hline & \multicolumn{2}{|c|}{ Type of diabetes } & $\begin{array}{l}\text { Age } \\
\text { (years) }\end{array}$ & $\begin{array}{l}\text { Duration of } \\
\text { diabetes } \\
\text { (years) }\end{array}$ & $\begin{array}{l}\text { Duration of polyneuro- } \\
\text { pathy (as assessed from } \\
\text { history) } \\
\text { (years) }\end{array}$ & $\begin{array}{l}\text { Duration of sexual dys- } \\
\text { function (as assessed } \\
\text { from history) } \\
\text { (years) }\end{array}$ \\
\hline $\begin{array}{l}\text { Sorbinil } \\
\quad \text { group }(n=27)\end{array}$ & 24 & 3 & $\begin{array}{l}48.7 \pm 10.4 \\
(29-65)\end{array}$ & $\begin{array}{l}20.7 \pm 11.1 \\
(5-48)\end{array}$ & $\begin{array}{l}6.1 \pm 4.6 \\
(1-15)\end{array}$ & $\begin{array}{l}4.8 \pm 2.7 \\
(0-11)\end{array}$ \\
\hline
\end{tabular}

Results expressed as mean $\pm \mathrm{SD}$ with ranges within parentheses

Table 2. Causes of drop out for nine patients excluded from analysis

\begin{tabular}{lll}
\hline & $\begin{array}{l}\text { Sorbinil } \\
\text { group }\end{array}$ & $\begin{array}{l}\text { Placebo } \\
\text { group }\end{array}$ \\
\hline Intercurrent disease & 1 & 1 \\
Non-cooperation & 1 & 0 \\
Skin erythema (sorbinil) & 2 & - \\
Unspecific adverse reaction & 0 & 1 \\
Signs of alcohol abuse & 0 & 1 \\
Unstable diabetes & 1 & 1 \\
\hline
\end{tabular}

avoided during the study, to prevent varying diabetic control from influencing nerve function [11].

A further nine patients were recruited for the study, but dropped out for reasons shown in Table 2.

Informed consent was obtained from all patients. Approval was given by the Ethics Committee of the Medical Faculty of the University of Uppsala and by the Drug Division of the Swedish Board of Health and Welfare.

\section{Drug administration}

A randomized double-blind parallel group design was used. All patients were given placebo during a 4-week run-in period (single-blind). They were then randomly allocated either to study treatment (sorbinil $250 \mathrm{mg}$ once daily) [12] (Pfizer Central Research, Sandwich, Kent, UK) or to placebo tablets and entered a 24-week treatment period (double-blind). Since carry-over effects were considered possible, it was decided not to use a cross-over design. The treatment period was followed by a wash-out period of 2 months.

Patient compliance was assessed by counting returned tablets and by serum sorbinil concentrations (performed by Robens Institute of Environmental Health and Safety, Guildford, Surrey, UK).

Concomitant medication: Eighteen patients received medical treatment for hypertension, three for angina pectoris, and one for depression. Such treatment was continued throughout the study. No drugs known to interfere with peripheral nerve function were used.

\section{Evaluation of effects of treatment}

The patients were examined on six occasions. Two baseline examinations were performed, one at the beginning and one at the end of the run-in period. Examinations followed at 4,12 and 24 weeks of treatment, and finally at the end of the 2-month wash-out period.

Clinical examination. A detailed history, including questioning for symptoms of peripheral nerve and sexual dysfunction, was taken at the first visit. Subjective effects and complaints were monitored at each visit. A neurological examination with emphasis on peripheral nerve function was performed on each occasion. Discriminative sen- sation was examined by figure writing with a knitting needle (dermolexia) [13] on the finger tips and the dorsum of the foot. Tendon reflexes were scored +++ (increased), ++ (normal), + (weak) or absent. All clinical examinations were conducted by the same observer (AB).

For nerve conduction velocities surface electrodes were used. Motor nerve conduction velocity was measured unilaterally in the ulnar and posterior tibial nerves. The F-wave latency was included [14] thus allowing evaluation of conduction also in the proximal parts of the motor nerves. Conduction time from distal stimulation site to muscle twitch (distal latency) was also monitored. Sensory nerve conduction velocity was measured in both sural nerves (orthodromic) and distal sensory latency in the ulnar nerve (antidromic from base of fifth finger to wrist). Averaging was applied. A thermocouple (Exacon Scientific Instruments, Taastrup, Denmark) was used for measurement of skin temperature of hands and feet on each occasion.

Sensory threshold determination. Quantitative measurements of sensory thresholds were performed for vibratory and thermal stimuli. For vibration sense a handheld vibrameter (Somedic, Stockholm, Sweden) was used [15]. Thresholds were determined at three sites: the dorsal aspect of the second metacarpal bone, the middle of the tibia and the dorsal aspect of the first metatarsal bone. Temperature sense was tested as the "warm-cold difference limen" with a "Marstock" thermostimulator (Somedic, Stockholm, Sweden) [16]. Determinations were made on the thenar surface of the hand and the lateral aspect of the dorsum of the foot.

Autonomic nerve function. Sweat function was assessed by recording the reduction of skin resistance in the palm of the hand and the sole of the foot following an arousal stimulus or a sudden deep inspiration (the so-called galvanic skin response, GSR). $\mathrm{Ag} / \mathrm{AgCl}$ electrodes with standard positions were used and the response was read off in volts (with standard amplification). Skin vasoconstriction was recorded by a photo-electric plethysmograph (van Gogh, Amsterdam, Netherlands) on the middle finger and the big toe, the pulse amplitude reduction following arousal or rapid inspiration being expressed as a percentage of the initial amplitude. These two methods are valuable for assessing skin sympathetic function in polyneuropathy [17]. Both responses are dependent on skin temperature (which was measured) and the emotional state of the subject. This means that results from single subjects cannot be compared, but group comparisons can be employed if interpreted with caution.

Vagal (parasympathetic) function was evaluated by monitoring ECG during deep breathing ( 6 breaths $/ \mathrm{min}$ ) $[18,19]$. RR-intervals were measured manually on a $25 \mathrm{~mm} / \mathrm{s}$ ECG paper display and the ratio between the longest and shortest interval was calculated for 10 consecutive breaths. The average of these 10 quotients was taken as a measure of the vagal influence on the heart. There is little change of heart rate variation over years [18] and the day-to-day coefficient of variation has been reported to be $9.3 \%$ [19]. 


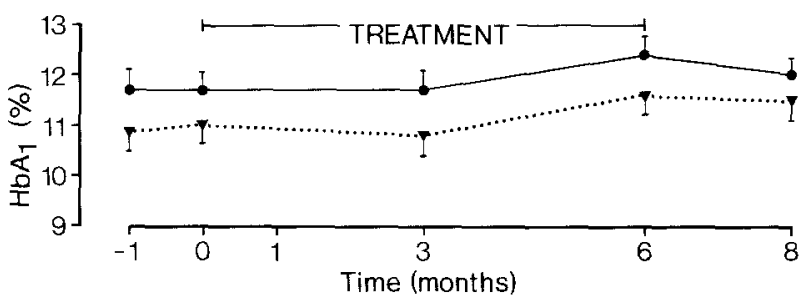

Fig. 1. Glycosylated haemoglobin $\left(\mathrm{HbA}_{1}\right)$ for the two groups of diabetic patients during the trial. Mean, SEM. $\nabla \cdot . . \nabla$ placebo. Treatment period between 0 and 6 months. Normal range for non-diabetic subjects $5-8 \%$

Table 3. Results of neurophysiological measurements in study patients at start of treatment period

\begin{tabular}{|c|c|c|c|}
\hline Variable & $\begin{array}{l}\text { Patients } \\
\text { receiving } \\
\text { sorbinil } \\
(n=27)\end{array}$ & $\begin{array}{l}\text { Patients } \\
\text { receiving } \\
\text { placebo } \\
(n=28)\end{array}$ & $\begin{array}{l}\text { Reference } \\
\text { value }^{\mathrm{a}}\end{array}$ \\
\hline \multicolumn{4}{|c|}{$\begin{array}{l}\text { Motor nerve conduction } \\
\text { velocity }(\mathrm{m} / \mathrm{s})\end{array}$} \\
\hline Ulnar nerve & $48.8 \pm 4.9$ & $47.8 \pm 4.7$ & $>48$ \\
\hline Tibial nerve & $34.4 \pm 4.7$ & $34.3 \pm 4.0$ & $>39$ \\
\hline \multicolumn{4}{|l|}{ F-wave latency (ms) } \\
\hline Ulnar nerve & $30.4 \pm 1.8$ & $30.6 \pm 2.3$ & $<28$ \\
\hline Tibial nerve & $57.9 \pm 5.5$ & $60.1 \pm 5.6$ & $<53$ \\
\hline \multicolumn{4}{|l|}{ Distal motor nerve } \\
\hline Ulnar nerve & $3.0 \pm 0.4$ & $3.1 \pm 0.6$ & $<3.0$ \\
\hline Tibial nerve & $7.1 \pm 1.8$ & $7.1 \pm 1.1$ & $<6.0$ \\
\hline \multicolumn{4}{|l|}{$\begin{array}{l}\text { Distal sensory nerve } \\
\text { latency (ms) }\end{array}$} \\
\hline Ulnar nerve & $2.7 \pm 0.3$ & $2.8 \pm 0.4$ & - \\
\hline \multicolumn{4}{|c|}{$\begin{array}{l}\text { Sensory nerve conduction } \\
\text { velocity }(\mathrm{m} / \mathrm{s})\end{array}$} \\
\hline Right sural nerve & $39.0 \pm 5.5$ & $38.6 \pm 4.9$ & $>39$ \\
\hline Left sural nerve & $38.7 \pm 5.0$ & $37.9 \pm 5.3$ & $>39$ \\
\hline
\end{tabular}

a for body height of $175 \mathrm{~cm}$. Results expressed as mean \pm SD

The autonomic tests were performed on only four occasions; at the beginning and the end of the run-in period, at the end of the treatment period, and at the end of the wash-out period.

Thus 19 numerical variables were assessed - 9 neurophysiological, 5 sensory, and 5 autonomic.

Laboratory tests. At each visit, except at that after the wash-out period, blood specimens were drawn for blood and platelet counts, serum urea and creatinine, sodium, potassium, uric acid, albumin, aspartate aminotransferase, alanine aminotransferase, alkaline phosphatase, bilirubin, lactate dehydrogenase, calcium and inorganic phosphate. Urinary albumin excretion was measured at each visit. Plasma sorbinil was analysed after 4 and 24 weeks of treatment.

$\mathrm{HbA}_{1}$ was determined with a microchromatographic method (BioRad laboratories, Richmond, California; intra- and inter-assay coefficients of variation $3 \%$ and $6 \%$, respectively [20]).

\section{Methods for result analysis}

Since $\mathrm{HbA}_{1}$ did not change during the run-in period $(p>0.70)$, indicating stable diabetic control, the mean of the two baseline values was calculated for all numerical variables. The change from this mean initial value to subsequent values was calculated for all variables and compared between the two groups of patients.

\section{Statistical methods}

Two-tailed Student's t-test for paired and unpaired observations, and multiple regression analysis, including $t$-test of significance of regression coefficients, were employed.

\section{Results}

\section{Diabetic control}

Throughout the study the sorbinil group showed slightly higher $\mathrm{HbA}_{1}$ levels than the placebo group (Fig.1). The difference was not significant on any occasion. The same was true for a similar, small difference in urine glucose concentration. Both groups displayed a slight increase of $\mathrm{HbA}_{1}$ level at the end of the treatment period. With the exception of two patients, who were excluded from analysis (Table 2), no major change of diabetic control occurred during the study.

\section{Clinical examination}

Three patients, all on sorbinil treatment, reported a marked overall improvement during treatment (after 1, 3 , and 6 months of treatment, respectively), with a return to their baseline levels of disability during the wash-out period. Reports of minor improvement were evenly distributed between the two patient groups. No statistically significant differences were seen.

At the first visit all patients but five (three on sorbinil, two on placebo) reported reduced sexual potency, defined as the patient's experience of impaired erective function. The three patients reporting an overall improvement also reported a marked improvement of their erectile ability during the treatment period, while the remaining patients reported only slight and variable changes.

Assessment of tendon reflexes and discriminative sensation did not reveal the development of any differences between the two patient groups. The clinical investigator assessed the overall clinical effect (from history and clinical examination) according to four categories: much better, better, no change, or worse. The distribution of patients on sorbinil was 3, 4, 18 and 2 in these categories, respectively. Corresponding figures for patients on placebo were $0,10,17$ and 1 . Thus only patients on active treatment appeared in the best category, but the remaining distribution did not suggest any significant clinical effect.

The three patients who reported a marked improvement were assessed to see whether they showed any specific characteristics. Their age was lower and their duration of diabetes shorter than the average for the treatment group. Their degree of polyneuropathy, as measured by the neurophysiological variables, tended to be less severe than the mean for the treatment group. A favourable change in the numerical variables, parallel 
MCV ulnaris

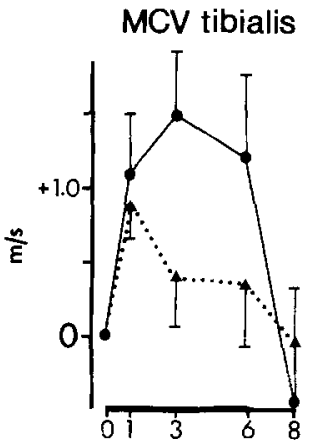

F ulnaris $F$ tibialis
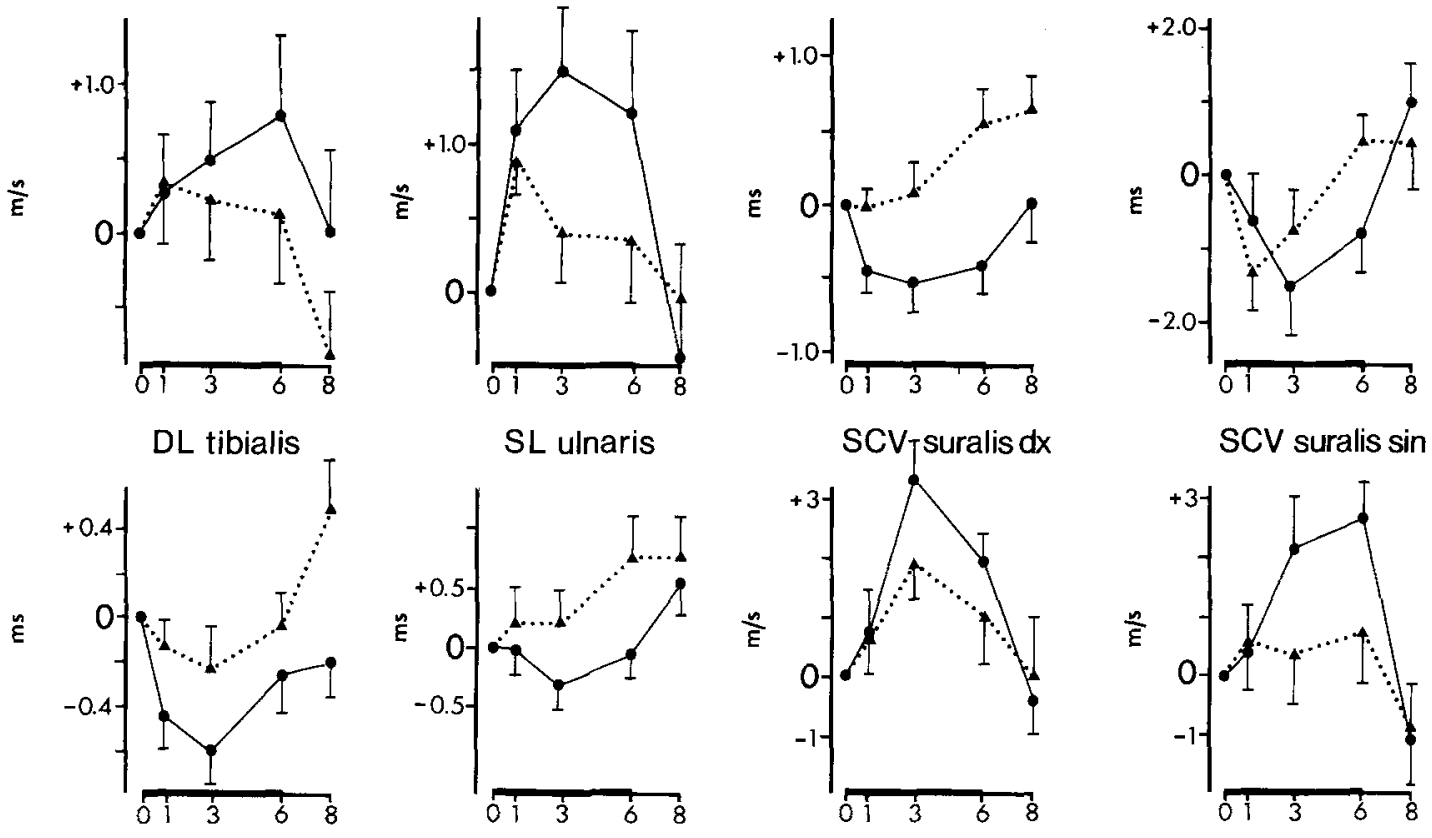

$\mathrm{SL}$ ulnaris
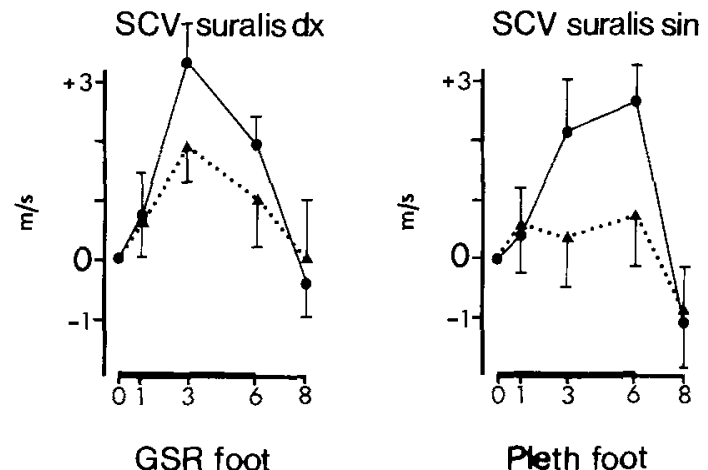

$R-R$ variation
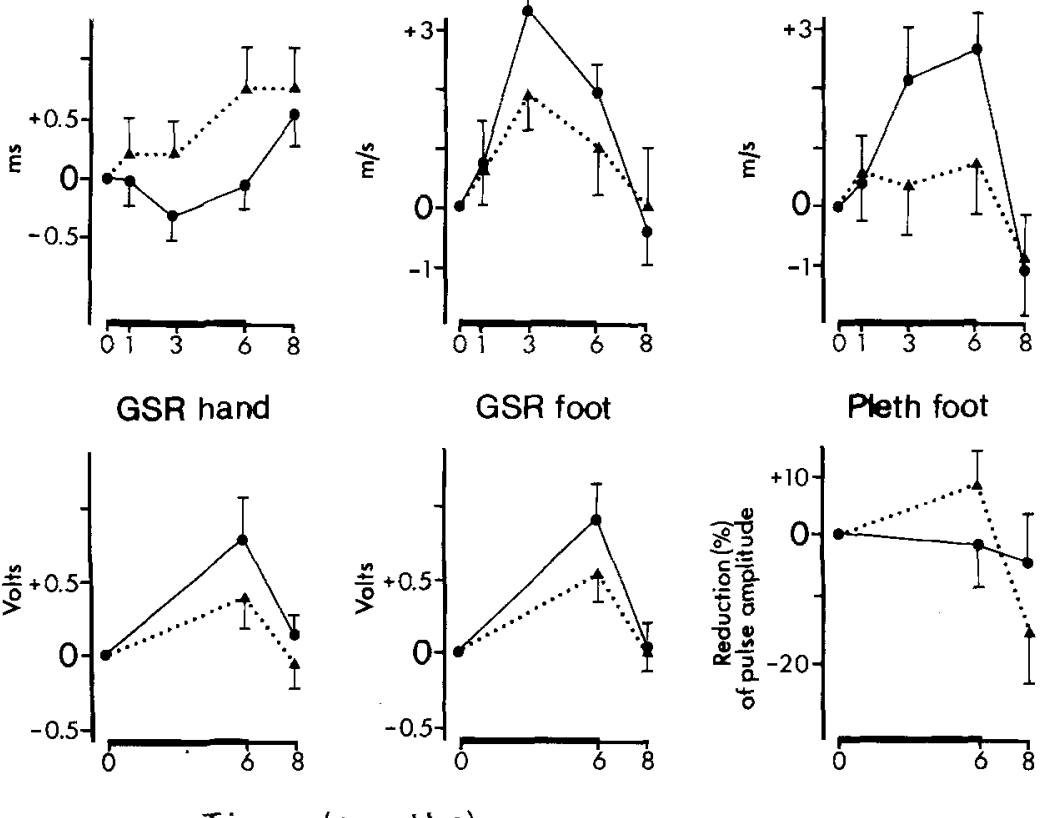

Time (months)

Fig. 2. Numerical variables for which changes during treatment and wash-out periods may suggest a relation to sorbinil treatment. Differences from zero level (= baseline value calculated as mean of two measurements during run-in period). Mean, SEM. $\longrightarrow$ Sorbinil group; $\Delta . . . .$. placebo. Six months treatment period indicated by thick time-scale line; wash-out period by thin time-scale line. MCV - motor nerve conduction velocity; F-F-wave latency; DL - distal motor nerve latency; SL - distal sensory nerve latency; SCV - sensory nerve conduction velocity; ulnaris - ulnar nerve; tibialis - posterior tibial nerve; suralis - sural nerve; $\mathrm{dx}$ - right side; sin - left side; R-R variation - RR-interval variation during deep breathing; GSR - galvanic skin response = reduction of skin resistance; Pleth - plethysmographic measurement of skin vasoconstriction; NB for distal latencies and F-wave latencies a reduction represents improvement; for all other variables an increase represents improvement

to the reported subjective improvement, was not seen, neither when all the tests were analysed nor when autonomic tests only were considered.

\section{Nerve conduction velocities}

The two patient groups were comparable before treatment (Table 3). No baseline differences were seen for any of the variables, with one exception [ $F$-wave latency of the tibial nerve was shorter for the sorbinil group at the first $(p<0.05)$, but not the second, baseline measurement].

Nine variables were assessed by the electrophysiological measurements. Eight (those shown in the upper two rows of Fig. 2) exhibited changes in sorbinil's favour, with a return towards baseline values at the end of the wash-out period. However, the difference reached statistical significance for only three of these eight variables (motor nerve conduction velocity of the posterior tibial nerve, F-wave latency of the ulnar nerve, and distal sensory latency of the ulnar nerve, Table 4). The remaining variable (distal motor latency of the ulnar nerve) showed virtually identical values for both groups throughout the study.

\section{Sensory thresholds}

The sensory threshold measurements were complicated by an even more pronounced variability than that observed previously [21]. Mean values for temperature sense were virtually identical for both groups throughout the study. Thresholds for vibratory sense showed without exception a slight tendency in favour of the 
Table 4. Significance levels or lowest p-values obtained for differences between patient groups

\begin{tabular}{|c|c|c|}
\hline Variable & p-value & $\begin{array}{l}\text { Time of } \\
\text { treatment } \\
\text { (months) }\end{array}$ \\
\hline \multicolumn{3}{|l|}{$\begin{array}{l}\text { Motor nerve conduction } \\
\text { velocity }\end{array}$} \\
\hline Ulnar nerve & $<0.35$ & 6 \\
\hline Tibial nerve & $<0.05$ & 3 \\
\hline \multicolumn{3}{|l|}{ F-wave latency } \\
\hline Ulnar nerve & $<0.05$ & 3 \\
\hline & $<0.01$ & 6 \\
\hline Tibial nerve & $<0.10$ & 6 \\
\hline \multicolumn{3}{|l|}{ Distal motor nerve } \\
\hline Tibial nerve & $<0.30$ & 3 \\
\hline \multicolumn{3}{|l|}{ Distal sensory nerve } \\
\hline Ulnar nerve & $<0.05$ & 6 \\
\hline \multicolumn{3}{|l|}{$\begin{array}{l}\text { Sensory nerve conduction } \\
\text { velocity }\end{array}$} \\
\hline Right sural nerve & $<0.30$ & 3 \\
\hline Left sural nerve & $<0.10$ & 6 \\
\hline RR-interval variation & $<0.05$ & 6 \\
\hline during deep breathing & $<0.01$ & Wash-out \\
\hline \multicolumn{3}{|l|}{$\begin{array}{l}\text { Reduction of skin } \\
\text { resistance }\end{array}$} \\
\hline Hand & $<0.30$ & 6 \\
\hline Foot & $<0.30$ & 6 \\
\hline \multicolumn{3}{|c|}{$\begin{array}{l}\text { Plethysmographic measurement } \\
\text { of skin vasoconstriction }\end{array}$} \\
\hline Foot & $<0.30^{\mathrm{a}}$ & 6 \\
\hline
\end{tabular}

a In favour of placebo

drug but no change with time similar to that seen in Figure 2 was observed.

\section{Autonomic nerve function}

For RR-interval variation during deep breathing a significant difference in favour of sorbinil was seen. It did not disappear during the wash-out period (Fig.2, Table 4). For sweat function, measured as reduction of skin resistance (GSR in Fig. 2), a non-significant difference in favour of active treatment was found in both the hand and the foot (Fig. 2, Table 4). Development over time was consistent with a possible effect of treatment. Skin vasoconstriction in the hand showed identical values for both groups but in the foot a non-significant difference was seen at the end of treatment (Fig. 2, Table 4); it was the only one of the 19 variables showing a tendency in favour of placebo.

\section{Effect of skin temperature on numerical variables}

Mean hand skin temperature did not differ between the two patient groups during the study, neither did mean foot temperature. However, some individuals exhibited considerable variation. Since all the measured variables (with the exception of RR-interval variation) are more or less dependent on tissue temperature in the extremities [22], the relationship between treatment groups, skin temperature of hand or foot and measured values was evaluated by multiple regression analysis. The analysis showed that skin temperature as a rule was a stronger determinant for the individual measured values than the type of treatment (sorbinil or placebo).

\section{Overall evaluation of numerical variables}

Of the 19 numerical variables, seven displayed virtually identical values for the two patient groups. Eleven of the remaining 12 variables showed a tendency, significant per se on only a few occasions, in favour of sorbinil treatment (Fig. 2). The temporal development, displayed by the shape of the graphs in Figure 2, is not evaluated by the above statistical tests. If these results are considered as the outcome of 12 independent observations with a probability of 0.5 for a tendency in either direction, there is a probability of $13: 2048$ of getting the observed proportion. Since F-wave latency is critically dependent on motor nerve conduction velocity, the two Fwave graphs were excluded, and the remaining $10 \mathrm{ob}-$ servations were evaluated. The probability of getting the observed 9:1 proportion is $11: 512$.

Side effects were few. Two patients receiving sorbinil developed an erythema after 10 and 21 days of treatment, respectively. The first one had fever, enlargement of lymph nodes, and diarrhoea, and required hospitalization for 2 weeks. The course was not typical for a drug reaction, but no other cause was found. A similar erythema has been observed in previous trials [6-8]. One sorbinil-treated patient developed a lichen ruber, verified by skin biopsy, but it was not considered to be due to treatment. One patient showed worsening of a seborrhoic dermatitis and was therefore withdrawn from the trial. He was, however, found to have received placebo.

Laboratory tests. Changes from baseline values or differences between the groups suggestive of unwarranted effects of the drug did not occur in any of the analyses.

Plasma sorbinil was detectable at both 1 and 6 months (mean values $9.8 \pm 4.1$ and $9.2 \pm 3.5 \mu \mathrm{g} / \mathrm{ml}$, respectively) in all patients receiving active treatment. Two patients had a much lower level at 6 months than at 1 month but they did not run a less favourable course than the average for any variable. Tablet counting did not reveal any lack of patient compliance.

\section{Discussion}

The present study suggests that minor improvement of peripheral nerve function occurs as a result of treatment with the aldose reductase inhibitor sorbinil. Only some 
of the differences in neurophysiological variables that appeared between the study groups during the treatment period were statistically significant (Fig. 2 and Table 4), but the changes with time, including the deterioration of the treated group during the wash-out period, strongly suggest a treatment effect. In fact, this was significant when a non-parametrical estimation of probability was made. However, the effects observed were not dramatic (it should be noted that Figure 2 displays only changes from baseline levels, not absolute values) and subjective improvement was reported by only three of the 27 patients on active treatment.

Whether the effects observed are related directly to diminished sorbitol and fructose accumulation, or to the increase of nerve myo-inositol content that has been shown to occur in animals treated by an aldose reductase inhibitor [23, 24], or to some other, undetermined, effect of the treatment, is unknown. The possibility of a non-specific increase in nerve conduction velocity, irrespective of the presence of diabetes, is excluded by animal findings $[23,25,26]$.

The results suggest that some improvement occurred in both somatic and autonomic nerve function. Diabetic autonomic neuropathy is usually considered irreversible [27], and previous studies with aldose reductase inhibitors in which autonomic tests were included have yielded variable results $[5,7,8]$. However, it might possibly be partly reversible, as improvement in cardiovascular reflex tests has been observed after long-term treatment with continuous insulin infusion [28, 29].

Regression analysis showed that skin temperature variation exerted a stronger influence than the type of treatment on individual changes in most of the electrophysiological variables. Temperature variation in individual patients may therefore have enhanced the differences observed between the groups on some occasions but caused a reduction on other occasions. Since, however, the observed differences between the groups (Fig.2) were not parallelled by similar differences in skin temperature, it is not likely that temperature variation contributed significantly to the results.

The beneficial effects of aldose reductase inhibitor treatment seen in the present trial, as well as their limited nature, are consistent with the findings of most previous controlled trials [5-9]. The duration of treatment of the present study was twice as long as that of any previous one, but the effects observed were no greater than those in previous studies.

In the present study the mean $\mathrm{HbA}_{1}$ levels indicated unsatisfactory metabolic control (Fig. 1). The degree of diabetic nerve damage was advanced (Table 3 ) and varied considerably between patients. Such features may make it more difficult to show a significant effect of treatment. With the exception of one study, in which all patients had only subclinical polyneuropathy [6], heterogeneity of the groups under study and a severe degree of polyneuropathy have been features of all the trials performed. Heterogeneity is a consequence of choosing to treat symptomatic patients who are in real need for treatment. On the other hand, treating asymptomatic patients may give rise to difficulties with patient compliance and also the expected benefits of treatment must outweigh any possible side effects.

There was a tendency, although non-significant, for the improvement in nerve conduction to be maximal halfway through the treatment period (Fig. 2). Plasma sorbinil analyses showed that this was not due to decreasing patient compliance. Judzewitsch et al. [6] reported an early, small, but significant, increase of nerve conduction velocity during 9 weeks of treatment, but progressive improvement with time was not observed and the time course of peroneal nerve conduction velocity even revealed a tendency to deterioration before treatment was withdrawn. The protective effect of aldose reductase inhibitor treatment against nerve conduction deficit in galactose fed rats was confined to a few weeks [30]. These observations are not conclusive but may suggest that the beneficial effect from an aldose reductase inhibitor is of limited duration. Whether the potent inhibitory effect of sorbinil on the polyol pathway is maintained during long-term treatment is unknown.

Also, it should be pointed out that there is no general agreement on the role of the sorbitol pathway in diabetic polyneuropathy [31, 32], and entirely different pathogenetic mechanisms, such as glycosylation of myelin proteins [33] and endoneurial hypoxia [34], are currently being discussed. Thus, it is possible that the present treatment is affecting a mechanism that has only a minor role in the pathogenesis. Furthermore, there may be reversible and irreversible components of the polyneuropathy, with only the first being amenable to treatment. These factors may explain the limited nature of the benefit observed in the present study.

Trials with aldose reductase inhibitors for even longer periods and with more homogenous groups of patients (but not in patients with only subclinical polyneuropathy) might cast light on the above questions. Also, it appears as important as ever to search for alternative pathogenetic mechanisms of, and thus alternative modes of treatment for, this common complication of diabetes mellitus.

Acknowledgements. Supported by the Swedish Medical Research Council, grant no. B84-14X-03546-10B, the Henning Larsson Fund for study of polyneuropathy, and a grant from Pfizer Research, Sandwich, UK. Mrs K. Wettervik assisted with conduction velocity measurements. E. Quensel, Department of Statistics, University of Uppsala, gave statistical advice.

\section{References}

1. Thomas PK, Eliasson SG (1984) Diabetic neuropathy. In: Dyck PJ, Thomas PK, Lambert EH, Bunge R (eds) Peripheral neuropathy. WB Saunders, Philadelphia, pp 1773-1810

2. Pirart J (1977) Diabète et complications dégénératives présentation d'une étude prospective portant sur 4400 cas observés entre 1947 et 1973. Diabete Metab (Paris) 3: 97-107, 173-182, 245-256 
3. Gabbay KH, Merola LO, Field RA (1966) Sorbitol pathway: presence in nerve and cord with substrate accumulation in diabetes. Science 151: 209-210

4. Handelsman DJ, Turtle JR (1981) Clinical trial of an aldose reductase inhibitor in diabetic neuropathy. Diabetes 30:459-464

5. Fagius J, Jameson S (1981) Effects of aldose reductase inhibitor treatment in diabetic polyneuropathy - a clinical and neurophysiological study. J Neurol Neurosurg Psychiatr 44: 991-1001

6. Judzewitsch RG, Jaspan JB, Polonsky KS, Weinberg CR, Halter JB, Halar E, Pfeifer MA, Vukadinovic C, Bernstein L, Schneider M, Lian K-Y, Gabbay KH, Rubenstein AH, Porte D Jr (1983) Aldose reductase inhibition improves nerve conduction velocity in diabetic patients. New Engl J Med 308: 119-125

7. Young RJ, Ewing DJ, Clarke BF (1983) A controlled trial of sorbinil, an aldose reductase inhibitor, in chronic painful diabetic neuropathy. Diabetes 32: 938-942

8. Jaspan J, Maselli R, Herold K, Bartkus C (1983) Treatment of severely painful diabetic neuropathy with an aldose reductase inhibitor: relief of pain and improved somatic and autonomic nerve function. Lancet 2: 758-762

9. Schouten JA, Heimans JJ, Popp-Snijders C, Boot H, van den Akker J, van der Veen EA (1984) A 3-month, placebo-controlled, efficacy study of sorbinil for diabetic neuropathy. Diabetologia 27: $329 \mathrm{~A}$

10. Peterson MJ, Sarges R, Aldinger CE, MacDonald DP (1979) CP45,634: A novel aldose reductase inhibitor that inhibits polyol pathway activity in diabetic and galactosemic rats. Metabolism 28 (Suppl): 456-461

11. Agardh C-D, Rosén I, Scherstén B (1983) Improvement of peripheral nerve function after institution of insulin treatment in diabetes mellitus. Acta Med Scand 213: 283-297

12. Foulds G, O'Brien MM, Bianchine JR, Gabbay KH (1981) Kinetics of an orally absorbed aldose reductase inhibitor, sorbinil. Clin Pharmacol Ther 30:693-700

13. Bergström J, Lindblom U, Norée L-O (1975) Preservation of peripheral nerve function in severe uremia during treatment with low protein high calorie diet and surplus of essential amino acids. Acta Neurol Scand 51:99-109

14. Lachman T, Shahani BT, Young RR (1980) Late responses as aids to diagnosis in peripheral neuropathy. $J$ Neurol Neurosurg Psychiatr 43: 156-162

15. Goldberg JM, Lindblom U (1979) Standardised method of determining vibratory perception thresholds for diagnosis and screening in neurological investigation. J Neurol Neurosurg Psychiatr 42: $793-80$

16. Fruhstorfer H, Lindblom U, Schmidt WG (1976) Method for quantitative estimation of thermal thresholds in patients. J Neurol Neurosurg Psychiatr 39: 1071-1075

17. Fagius J, Wallin BG (1980) Sympathetic reflex latencies and conduction velocities in patients with polyneuropathy. J Neurol Sci 47: 449-461

18. Mackay JD, Page MMcB, Cambridge J, Watkins PJ (1980) Diabetic autonomic neuropathy. The diagnostic value of heart rate monitoring. Diabetologia 18: 471-478

19. Pfeifer MA, Cook D, Brodsky J, Tice D, Reenan A, Swedine S, Halter JB, Porte D Jr (1982) Quantitative evaluation of cardiac parasympathetic activity in normal and diabetic man. Diabetes 31: $339-345$

20. Wålinder $O$ (1980) A rapid microchromatographic method for determination of hemoglobin $\mathrm{A}_{1}$. Upsala J Med Sci 85:151-158

21. Fagius J, Wahren LK (1981) Variability of sensory threshold determination in clinical use. J Neurol Sci 51:11-27

22. Halar EM, DeLisa JA, Brozovich FV (1980) Nerve conduction velocity: Relationship of skin, subcutaneous and intramuscular temperatures. Arch Phys Med Rehab 61: 199-203

23. Mayer $\mathrm{JH}$, Tomlinson DR (1983) Prevention of defects of axonal transport and nerve conduction velocity by oral administration of myoinositol or an aldose reductase inhibitor in streptozotocin-diabetic rats. Diabetologia 25:433-438

24. Finegold D, Lattimer SA, Nolle S, Bernstein M, Greene DA (1983) Polyol pathway activity and myo-inositol metabolism. A suggested relationship in the pathogenesis of diabetic neuropathy. Diabetes 32: $988-992$

25. Yue DK, Hanwell MA, Satchell PM, Turtle JR (1982) The effect of aldose reductase inhibition on motor nerve conduction velocity in diabetic rats. Diabetes 31: 789-794

26. Tomlinson DR, Moriarty RJ, Mayer JH (1984) Prevention and reversal of defective axonal transport and motor nerve conduction velocity in rats with experimental diabetes by treatment with the aldose reductase inhibitor sorbinil. Diabetes 33: 470-476

27. Clarke BF, Ewing DJ, Campbell IW (1979) Diabetic autonomic neuropathy. Diabetologia 17: 195-212

28. Cicmir I, Kashiwagi S, Berger H, Koschinsky T, Gries FA (1983) Improvement of autonomic nerve functions after one year of continuous subcutaneous insulin infusion. Diabetologia 25: 147 (Abstract)

29. Sachse G, Neuzner J, Federlin K (1983) Long-term effect of continuous subcutaneous insulin infusion therapy on the autonomic diabetic neuropathy of the cardiovascular system. Diabetologia 25: 191 (Abstract)

30. Gabbay KH (1973) Role of sorbitol pathway in neuropathy. In: Camerini-Dávalos RA, Cole HS (eds) Vascular and neurological changes in early diabetes. Academic Press, New York, pp 417-424

31. Clements RS Jr (1982) Myoinositol metabolism in diabetic neuropathy. In: Goto $Y$, Horiuchi A, Kogure K (eds) Diabetic neuropathy. Excerpta Medica, Amsterdam, pp 19-25

32. Winegrad AI, Simmons DA, Martin DB (1983) Has one diabetic complication been explained? New Engl J Med 308: 152-154

33. Vlassara H, Brownlee M, Cerami A (1981) Nonenzymatic glycosylation of peripheral nerve protein in diabetes mellitus. Proc Natl Acad Sci 78: 5190-5192

34. Tuck RR, Schmelzer JD, Low PA (1984) Endoneurial blood flow and oxygen tension in the sciatic nerves of rats with experimental diabetic neuropathy. Brain 107:935-950

Received: 14 December 1984

and in revised form: 8 May 1985

Dr. Jan Fagius

Department of Neurology

University Hospital

S-751 85 Uppsala, Sweden 